\title{
Acid proteinase secreted by Candida tropicalis: functional analysis of preproregion cleavages in C. tropicalis and Saccharomyces cerevisiae
}

\author{
Giuseppe Togni, ${ }^{1,2}$ Dominique Sanglard, ${ }^{2}$ Manfredo Quadroni, ${ }^{3}$ \\ Stephen I. Foundling ${ }^{4}$ and Michel Monod ${ }^{1}$
}

Author for correspondence: M. Monod. Tel: +41 2131403 76. Fax: +41 213140378.

\footnotetext{
1 Laboratoire de Mycologie, Service de Dermatologie, Centre Hospitalier Universitaire Vaudois, 1011 Lausanne, Switzerland

2 Institut de Microbiologie, Centre Hospitalier Universitaire Vaudois, 1011 Lausanne, Switzerland

3 Laboratorium für Biochemie, ETH-Zentrum, 8092 Zürich, Switzerland

4 Laboratory of Protein Crystallography, Protein Studies Program, Oklahoma Medical Research Foundation, Oklahoma City, Oklahoma 73104, USA
}

\begin{abstract}
The $40 \mathrm{kDa}$ secreted aspartyl proteinase (Sapt1) of Candida tropicalis is a pepsin-like enzyme encoded by the SAPT1 gene. According to the deduced amino acid sequence, Sapt1 has a putative preproregion of 60 amino acids preceding the mature enzyme. Maturation and processing of Sapt1 was analysed in C. tropicalis and Saccharomyces cerevisiae strains expressing wildtype or mutated forms of SAPT1. In S. cerevisiae, the glycosylated $46 \mathrm{kDa}$ proenzyme was converted to the mature $40 \mathrm{kDa}$ form of Sapt1 by KEX2dependent proteolytic cleavage following the Lys ${ }^{59}$-Arg ${ }^{60}$ sequence. The replacement of Lys ${ }^{59}-$ Arg $^{60}$ by Lys ${ }^{50}-$ Gly ${ }^{60}$ revealed that the precursor can be processed by an autocatalytic cleavage. This alternative processing pathway to produce mature Sapt1 is less efficient than the Kex2-mediated pathway. Finally, it was shown that in C. tropicalis and S. cerevisiae the removal of the proregion was a prerequisite for the secretion of Sapt1.
\end{abstract}

Keywords: Candida tropicalis, Saccharomyces cerevisiae, secreted aspartyl proteinase, Kex2 endopeptidase, secretion

\section{INTRODUCTION}

The yeasts of the genus Candida are commensals of the gastrointestinal and genitourinary tracts capable of causing severe candidiasis in immunocompromised patients (Horn et al., 1985; Kwon-Chung \& Bennett, 1992; Wingard et al., 1979). Medically important species of Candida produce one dominant secreted aspartic proteinase (Sap) in vitro when cultured in media containing protein as the sole nitrogen source (for a review see Ogrydziak, 1993). Sap2, Sapt1 and Sapp1 refer to the proteinases secreted by $C$. albicans, $C$. tropicalis and $C$. parapsilosis, respectively (Monod $e t$ al., 1994). These wellcharacterized enzymes have been suggested to be potential virulence factors of these yeasts (Odds, 1988).

Recently, C. albicans has been shown to secrete other Saps. The $C$. albicans WO-1 switching strain can secrete Sap2 and two additional Saps in the opaque form (White et al., 1993), and seven genes ( $S A P$ ) encoding distinct aspartic proteinases of $C$. albicans have been cloned and sequenced (Hube et al., 1991; Miyasaki et al., 1994; Monod et al., 1994; Morrow et al., 1992; White et al., 1993; Wright et al., 1992). During in vitro serum-induced germ tube

Abbreviations: ER, endoplasmic reticulum; Sap, secreted aspartyl proteinase. formation $C$. albicans produces mRNAs that hybridize with the genes SAP4, SAP5 and SAP6 (Hube et al., 1994). The existence of $S A P$ multigene families in $C$. tropicalis and $C$. parapsilosis has also been demonstrated (Monod et al., 1994). However, only one gene of $C$. tropicalis (SAPT1; Togni et al., 1991) and two of $C$. parapsilosis (SAPP1 and SAPP2; de Viragh et al., 1993) have been cloned and sequenced to date.

A comparison of the $\mathrm{N}$-terminal amino acid sequences of six Saps (Sap1, Sap2, Sap3, Sapp1, Sapp2 and Sapt1) determined by Edman degradation, together with the amino acid sequences deduced from the corresponding $S A P$ genes, indicates that these enzymes are translated as a preproenzyme, approximately 60 amino acids larger than the mature form. All the precursors show similar processing sites. The 60 amino acid prepropeptide has a signal sequence of 14-21 amino acids with one to four putative signal peptidase cleavage sites (Von Heijne, 1986) and two Lys-Arg sequences, one of which is immediately before the N-terminus of the mature form of the enzyme. The Arg-Lys sequences are known to be cleaved by the Kex 2 proteinase in Saccharomyces cerevisiae (Julius et al., 1984).

In this paper we report studies on the secretion of Sapt1 by $C$. tropicalis and $S$. cerevisiae strains carrying the wild- 
type or mutated forms of $S A P T 1$. With these yeasts we have determined the structures of the intracellular precursors of Sapt1, and evaluated the role of the processing sites in the secretion of this enzyme. The different steps of maturation and secretion of Sapt1 deduced here may be used as a model for the other Candida Saps.

\section{METHODS}

Organisms. C. tropicalis ATCC 750 is a wild-type pathogenic strain. C. tropicalis DSY59 (ade2/ade2, sapt1 $:: \lambda /$ sapt1 $1:: \lambda$ ) (Sanglard et al., 1992) was chosen as the recipient for transformation. The strains of $S$. cerevisiae used in this study are listed in Table 1 and the characteristics of sec mutants are described in Table 3. Escherichia coli DH5 $\alpha$ (Hanahan, 1983) was chosen as a carrier for recombinant plasmids. E. coli CJ236 (Kunkel $e t$ al., 1987), E. coli TG1 (Gibson, 1984) and bacteriophage M13 mp18 were used for site-directed mutagenesis.

Growth media. C. tropicalis ATCC 750, C. tropicalis DSY59 and non-transformed $S$. cerevisiae strains were maintained on Sabouraud agar medium (Diagnostic Pasteur). Transformed $C$. tropicalis and $S$. cerevisiae strains were maintained on minimal medium (MM) plates $[0.67 \%(\mathrm{w} / \mathrm{v})$ Yeast Nitrogen Base (YNB, Difco), $2 \%(\mathrm{w} / \mathrm{v})$ glucose, $1.5 \%(\mathrm{w} / \mathrm{v})$ agar] containing $20 \mu \mathrm{g}$ $\mathrm{ml}^{-1}$ of appropriate supplements. Non-inducing liquid cultures were carried out in Sabouraud medium (Diagnostic Pasteur) or supplemented liquid MM. Liquid $S A P T 1$ induction media were bovine serum albumin (BSA) medium $[0.2 \%(\mathrm{w} / \mathrm{v}) \mathrm{BSA}$,
$1.7 \%(\mathrm{w} / \mathrm{v})$ YNB without amino acids and ammonium salts (Difco), $2 \%(\mathrm{w} / \mathrm{v}$ ) glucose, $\mathrm{pH} 4.0]$ for $C$. tropicalis and galactose medium $[0.67 \%(\mathrm{w} / \mathrm{v}) \mathrm{YNB}, 2 \%(\mathrm{w} / \mathrm{v})$ galactose] for S. cerevisiae strains. Secreted proteolytic activity was monitored using BSA plates [BSA medium solidified with $1.5 \%(\mathrm{w} / \mathrm{v})$ agar] for C. tropicalis and supplemented glucose/galactose plates $[0.67 \%(\mathrm{w} / \mathrm{v}) \mathrm{YNB}, 2 \%(\mathrm{w} / \mathrm{v})$ glucose, $2 \%(\mathrm{w} / \mathrm{v})$ galactose, $2 \% \mathrm{BSA}, 1.5 \%$ (w/v) agar, $\mathrm{pH} 4.0 \mathrm{~J}$ for $S$. cerevisiae strains. Induced cultures were incubated for $4 \mathrm{~d}$ at $30^{\circ} \mathrm{C}$ and proteolytic activity was observed as a clear zone around the colonies in the absence of any staining procedure.

Plasmid constructions and site-directed mutagenesis. The plasmid pDS22 (Sanglard et al., 1992), containing the SAPT1 gene, was used to transform $C$. tropicalis DSY59. The following mutagenesis strategy for SAPT1 was chosen. The $1297 \mathrm{bp}$ HindIII-KpnI fragment (Fig. 1) was excised from pMTL21-E4 (Togni et al., 1991), which is a plasmid containing the whole $S A P T 1$ gene, and cloned in the bacteriophage M13 mp18, thus generating M13 mp18-HK1.3. This plasmid was mutated using the U-DNA mutagenesis kit (Boehringer), which is based on the method developed by Kunkel et al. (1987). Synthetic oligonucleotides used in site-directed mutagenesis are described in Table 2 and Fig. 1. The presence of mutations was verified by nucleotide sequencing. The 1200 bp $B g / \mathrm{II}-K p n \mathrm{I}$ fragment of pDS22 was excised and replaced with the different mutated 1200 bp $B g / \mathrm{II}-$ $K p n$ I fragments from M13 mp18-HK1.3, generating the plasmids listed in Table 1.

Table 1. S. cerevisiae strains and plasmids used in this study

\begin{tabular}{|c|c|c|}
\hline Strain or plasmid & Genotype and characteristics* & Reference or source \\
\hline \multicolumn{3}{|l|}{ S. cerevisiae } \\
\hline GRF18 & $\alpha$, leu2-3, leu2-112, bis3-11, bis3-15 & Sengstag \& Hinnen (1987) \\
\hline RSY10 & $\alpha, \sec 1-1$, leu $2-3$, leu $2-112$, ura $3-52$ & R. Haguenauer-Tsapis $\dagger$ \\
\hline RSY9 & $\alpha, \sec 7-1$, leu2-3, leu2-112, ura3-52 & R. Haguenauer-Tsapis \\
\hline HMSF176 & $\alpha, \sec 18-1$, leu2-3, leu2-112 & R. Haguenauer-Tsapis \\
\hline RSY12 & $\alpha, \sec 53-6$, leu2-3, leu2-112, ura3-52 & R. Haguenauer-Tsapis \\
\hline RSY455 & $a, \sec 61-3$, leu2-3, bis4, ura3-52 & R. Haguenauer-Tsapis \\
\hline $\operatorname{Tr} 1625$ & $a$, ura3-52, kex2::leu2-3, leu2-112 & A Hinnen $\ddagger$ \\
\hline \multicolumn{3}{|l|}{ Plasmids } \\
\hline pDS22 & pMK16-derived plasmid carrying the $S A P T 1$ gene & Sanglard et al. (1992) \\
\hline pDS22-46 & Derivative of pDS22 mutated with oligonucleotide 1 & This study \\
\hline pDS22-97 & Derivative of pDS 22 mutated with oligonucleotide 2 & This study \\
\hline pDS22-178 & Derivative of pDS 22 mutated with oligonucleotide 3 & This study \\
\hline pDS22-275 & Derivative of pDS22 mutated with oligonucleotide 4 & This study \\
\hline pDS22-833 & Derivative of pDS22 mutated with oligonucleotide 5 & This study \\
\hline YEp51 & E. coli-S. cerevisiae shuttle vector & Rose \& Broach (1991) \\
\hline YEp51-SAPT1 & YEp51-derived plasmid carrying the $S A P T 1$ gene & This study \\
\hline YEp51-SAPT1-46 & Derivative of YEp51-SAPT1 mutated with oligonucleotide 1 & This study \\
\hline YEp51-SAPT1-97 & Derivative of YEp51-SAPT1 mutated with oligonucleotide 2 & This study \\
\hline YEp51-SAPT1-178 & Derivative of YEp51-SAPT1 mutated with oligonucleotide 3 & This study \\
\hline YEp51-SAPT1-275 & Derivative of YEp51-SAPT1 mutated with oligonucleotide 4 & This study \\
\hline YEp51-SAPT1-833 & Derivative of YEp51-SAPT1 mutated with oligonucleotide 5 & This study \\
\hline YEp51-SAPT1-97/178 & Derivative of YEp51-SAPT1 mutated with oligonucleotide 2 and 3 & This study \\
\hline YEp51-SAPT1-178/275 & Derivative of YEp51-SAPT1 mutated with oligonucleotide 3 and 4 & This study \\
\hline YEp51-URA3-SAPT1 & Derivative of YEp51-SAPT1, carrying the $U R A 3$ gene & This study \\
\hline
\end{tabular}

* For details of oligonucleotides 1 to 5 , see also Table 2 .

† R. Haguenauer-Tsapis, Université Paris VII, Paris, France.

$\ddagger$ A. Hinnen, Ciba-Geigy AG, Basel, Switzerland. 
Table 2. Oligonucleotide primers used for site-directed mutagenesis

\begin{tabular}{|lccc|}
\hline $\begin{array}{l}\text { Oligo- } \\
\text { nucleotide }\end{array}$ & Oligonucleotide sequence & $\begin{array}{c}\text { Codon: } \\
\text { wild-type } \rightarrow \text { mutant }\end{array}$ & $\begin{array}{c}\text { Amino acid: } \\
\text { wild-type } \rightarrow \text { mutant }\end{array}$ \\
\hline 1 & ATT GCT CTT CCT TTT GCT & GCT $\rightarrow$ CCT & Ala $^{\mathbf{1 6}} \rightarrow$ Pro $^{\mathbf{1 6}}$ \\
2 & ATT GAG AAA GGA ACC GAC A & AGA $\rightarrow$ GGA & Arg $^{\mathbf{3 3}} \rightarrow$ Gly $^{\mathbf{3 3}}$ \\
4 & ATT CAA AAG GGA AGT GAT G & AGA $\rightarrow$ GGA & Arg $^{\mathbf{6 0}} \rightarrow$ Gly $^{\mathbf{6 0}}$ \\
5 & TT GTC ATT GTC ACC GGT TC & GAC $\rightarrow$ GTC & Asp $^{\mathbf{2 2}} \rightarrow$ Val $^{\mathbf{9 2}}$ \\
& TT GTT TTG GTC TCT GGT AC & GAC $\rightarrow$ GTC & Asp $^{278} \rightarrow$ Val $^{\mathbf{2 7 8}}$ \\
\hline
\end{tabular}

(a)

EcoRI

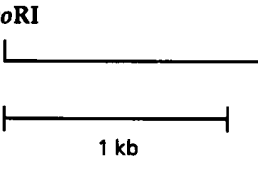

(b)

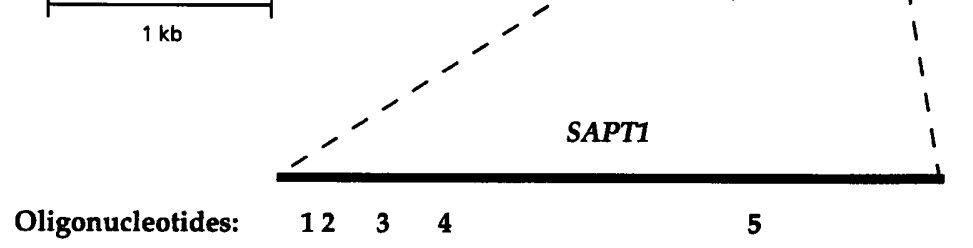

(c)

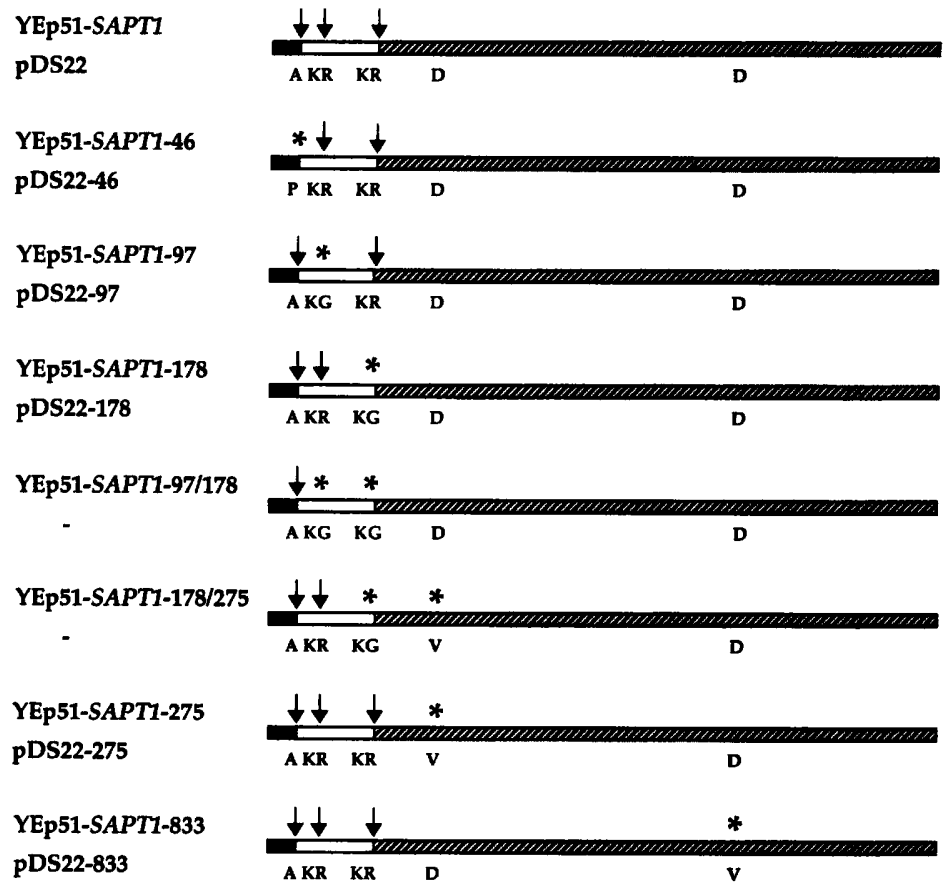

Fig. 1. (a) Restriction map of the $4.0 \mathrm{~kb}$ ECORI fragment carrying the SAPT1 gene. (b) Localization of the oligonucleotides (1-5) used for site-directed mutagenesis. (c) Representation of the proteins encoded by the plasmids listed on the left and constructed as described in Table 1. $S$. cerevisiae strains were transformed with YEp51 derivatives and the $C$. tropicalis strain was transformed with pDS22 derivatives. The signal sequence is indicated as a solid black box, the proregion is symbolized by an open rectangle and the mature Sapt1 sequence by diagonal lines. The arrows indicate the positions of the potential processing sites. The asterisks mark the regions mutated by site-directed mutagenesis. The one-letter amino acid code indicates the sequence of the protein encoded by each plasmid.
The YEp51 expression plasmid (Rose \& Broach, 1991) was used to transform $S$. cerevisiae. The $1182 \mathrm{bp} S A P T 1$ coding region was amplified by PCR using the primers GCG'TCGACAAAATGGCTACCCATTTTC (26-mer) and GCGGATCCATTCAATTATACTTTGAC (27-mer), allowing the $S A P T 1$ gene to be flanked with Sall and BamHI restriction sites. The PCR was performed following standard protocols (Innis et al., 1990). The amplified fragment was cloned in the SalI and BamHI site of YEp51 and of bacteriophage M13 mp18 DNA, generating YEp51-SAPT1 and M13 mp18-SAPT1, respectively, for sitedirected mutagenesis. After mutagenesis, the $S A P T 1$ amplified region was excised from M13 mp18-SAPT1 using SalI and $B a m \mathrm{HI}$ and cloned into YEp51, generating the YEp51-SAPT1derived plasmids listed in Table 1. 
In order to construct a plasmid for the transformation of the $S$. cerevisiae strain $\operatorname{Tr} 1625$ (Table 1), the $U R A 3$ gene was introduced into the YEp51 plasmid as follows. The $1.2 \mathrm{~kb}$ $H$ indIII fragment containing the entire $U R A 3$ gene was isolated from YEp24. A 0.1 kb HindIII fragment of YEp51 was excised and replaced by the $1.2 \mathrm{~kb} H$ indIII $U R A 3$ fragment, generating YEp51-URA3-SAPT1 (Table 1).

Yeast transformations and plasmid preparation. S. cerevisiae was transformed by the lithium acetate method (Ito et al., 1983). C. tropicalis cells were protoplasted and transformed as described by Sanglard et al. (1992).

Yeast plasmids were extracted from cells of $C$. tropicalis and $S$. cerevisiae grown overnight at $30^{\circ} \mathrm{C}$ in $50 \mathrm{ml}$ supplemented MM. Cells were harvested, washed with $1 \mathrm{M}$ sorbitol, suspended in $10 \mathrm{ml}$ of SCEM medium (1 M sorbitol, $100 \mathrm{mM}$ sodium citrate, $25 \mathrm{mM}$ EDTA, $15 \mathrm{mM} \beta$-mercaptoethanol, $\mathrm{pH} \mathrm{5.8)}$ in the presence of $5 \mathrm{U}$ lyticase (Sigma) and incubated at $30^{\circ} \mathrm{C}$ for $30 \mathrm{~min}$. After lysis of sedimented protoplasts following the standard alkaline lysis protocol for bacterial plasmid preparations, yeast plasmids were purified using anion-exchange resin columns (Qiagen system, Kontron, Switzerland). One half of the recovered plasmid DNA was analysed on agarose gel following digestion with restriction enzymes.

In vitro translation. C. tropicalis total RNA was extracted following the guanidium thiocyanate phenol/chloroform protocol (Chomczynski \& Sacchi, 1987) after breaking sedimented cells with a mortar and pestle under liquid nitrogen. In vitro translation was performed for $90 \mathrm{~min}$ at $37^{\circ} \mathrm{C}$ in a final volume of $50 \mu \mathrm{l}$ containing $5 \mu \mathrm{g}$ total RNA, $25 \mu \mathrm{l}$ rabbit reticulocyte lysate and $50 \mu \mathrm{Ci}(1.85 \mathrm{MBq})$ Trans $-{ }^{35} \mathrm{~S}-\mathrm{Label}(\mathrm{ICN})$.

Sapt1 production and detection. $C$. tropicalis cells were grown at $30^{\circ} \mathrm{C}$ in YPD medium to an $\mathrm{OD}_{660}$ of 1.0 , sedimented and resuspended to an $\mathrm{OD}_{660}$ of 1.0 in $\mathrm{BSA}$ medium and grown for $3 \mathrm{~d}$ at $30^{\circ} \mathrm{C}$. Sapt 1 produced by $C$. tropicalis cells was purified by ion-exchange chromatography as previously described (Togni et al., 1991). S. cerevisiae cells were grown at $30^{\circ} \mathrm{C}$ in supplemented $\mathrm{MM}$ medium to an $\mathrm{OD}_{660}$ of $1 \cdot 0$, sedimented and resuspended to an $\mathrm{OD}_{660}$ of 1.0 in supplemented galactose medium and grown for $3 \mathrm{~d}$ at $30^{\circ} \mathrm{C}$. S. cerevisiae secreted proteins were recovered by trichloroacetic acid (TCA) precipitation. The proteins from $C$. tropicalis and $S$. cerevisiae samples were resuspended in Laemmli gel-loading buffer (Laemmli, 1970) at 1:100 of the original volume, separated by SDS-PAGE according to the method of Laemmli (1970) and analysed by Coomassie blue staining and immunoblotting. Immunoblotting was performed by passive transfer of proteins from the SDS-PAGE gel onto a nitrocellulose membrane according to Monod et al. (1991), with a 1:1000 dilution of the antiserum.

$\mathbf{N}$-terminal sequence of proteins secreted by $\mathbf{S}$. cerevisiae harbouring YEp51-SAPT1-178. S. cerevisiae cells carrying YEp51-SAPT1-178 were induced for Sapt1 production as described above. The supernatant was separated from yeast cells and Pepstatin A $\left(40 \mu \mathrm{g} \mathrm{ml}^{-1}\right)$ was added in order to inhibit Sapt1 enzymic activity. The secreted Sapt1 forms were purified in presence of Pepstatin A ( $\left.40 \mu \mathrm{g} \mathrm{ml}^{-1}\right)$ by ion-exchange chromatography as previously described (Togni et al., 1991) for Sapt1 produced by $C$. tropicalis. The recovered proteins were then separated by Tricine-SDS-PAGE and transferred onto PVDFImmobilon membranes (Millipore). After staining with Coomassie blue, the protein bands were cut out and analysed with a gas-phase sequenator $470 \mathrm{~A}$ (Applied Biosystems) with on-line PTH-derivative analyser $120 \mathrm{~A}$.
Antibodies. Polyclonal antibodies were raised in rabbits as previously described (Monod et al., 1991) by use of purified Sapt1 as the immunogen. Monoclonal antibody FX7-10 was obtained from a fusion experiment using mice immunized against $C$. tropicalis DSM 4238 SAPT1 proteinase and $C$. albicans ATCC 48867 Sap2 proteinase. This antibody was kindly provided by Dr M. Borg-von Zepelin (Göttingen).

Protein labelling and immunoprecipitation. $C$. tropicalis cells were grown at $30^{\circ} \mathrm{C}$ in YPD medium to an $\mathrm{OD}_{660}$ of 1.0 , sedimented and resuspended to an $\mathrm{OD}_{660}$ of 1.0 in BSA medium. Typically, a $50 \mathrm{ml}$ culture was grown for $24 \mathrm{~h}$ at $30^{\circ} \mathrm{C}$ before radiolabelling. A sample of $1 \mathrm{ml}$ was transferred into a microfuge tube and $50 \mu \mathrm{Ci}(1.85 \mathrm{MBq})$ Trans- ${ }^{35} \mathrm{~S}$-Label was added. After $120 \mathrm{~min}$ incubation at $30^{\circ} \mathrm{C}$, protein synthesis was stopped with $100 \mathrm{mM}$ sodium azide. The proteins in the supernatant were precipitated with $200 \mu \mathrm{l}$ of $100 \%$ (w/v) TCA and incubated for $5 \mathrm{~min}$ on ice, centrifuged and resuspended in $50 \mu \mathrm{l}$ gel-loading buffer. For immunoprecipitation of intracellular proteins, the cells were pelleted, resuspended in $200 \mu \mathrm{l}$ $1.8 \mathrm{M} \mathrm{NaOH}, 1.2 \mathrm{M} \beta$-mercaptoethanol, and incubated for $5 \mathrm{~min}$ on ice. After addition of $200 \mu \mathrm{l} 10 \%$ (w/v) TCA, the mixture was incubated for $5 \mathrm{~min}$ on ice, centrifuged and resuspended in $50 \mu \mathrm{l} \mathrm{Laemmli} \mathrm{gel-loading} \mathrm{buffer.} \mathrm{The} \mathrm{samples}$ were heated to $95^{\circ} \mathrm{C}$ for $5 \mathrm{~min}$. S. cerevisiae proteins were labelled as described for $C$. tropicalis, except that cells were grown in supplemented MM medium and induction was performed by culture in supplemented galactose medium for $9 \mathrm{~h}$. The sec mutants were grown for $1 \mathrm{~h}$ at the restrictive temperature of $37^{\circ} \mathrm{C}$ before radiolabelling.

Immunoprecipitation was performed as previously described (Franzusoff et al., 1991). Immunoprecipitated proteins were suspended in $50 \mu \mathrm{l}$ gel-loading buffer and heated to $95^{\circ} \mathrm{C}$ for $5 \mathrm{~min}$. Protein samples $(10 \mu \mathrm{l})$ were separated by SDS-PAGE using a $9 \%(\mathrm{w} / \mathrm{v})$ polyacrylamide gel and analysed by fluorography (Chamberlain, 1979).

Tunicamycin, brefeldin $\mathbf{A}$ and endoglycosidase $\mathbf{H}$ treatments. Tunicamycin $\left(10 \mu \mathrm{g} \mathrm{ml}^{-1}\right)$ was used to prevent protein glycosylation (Doms et al., 1989) and brefeldin A $\left(5 \mu \mathrm{g} \mathrm{ml}^{-1}\right)$ was used to block the translocation of the proteins through the Golgi apparatus (Duksin et al., 1982). Sapt1 synthesis was derepressed as described above and the drugs were added $1 \mathrm{~h}$ before radiolabelling the culture samples. Endoglycosidase $\mathrm{H}$ digestion was carried out on immunoprecipitated labelled material following the protocol described by Monod et al. (1989).

\section{RESULTS}

\section{Expression of SAPT1 in S. cerevisiae}

S. cerevisiae GRF18 and sec mutants were used as tools to investigate the secretion pathway of Sapt1 in order to identify the intermediate precursors of this protein and to study the effect of point mutations of putative processing sites in the preprosequence. Several reports have shown that $S$. cerevisiae can secrete heterologous extracellular gene products in enzymically active forms (Sato et al., 1986; Tatsumi et al., 1989; Yamashita et al., 1987). Notably, their N-termini were processed correctly by the use of the native pre and prepro sequences. To construct the plasmid for the expression of Sapt1 in S. cerevisiae, a 1182 bp fragment containing the entire prepro and mature coding region was amplified by PCR and inserted into YEp51, just downstream of the inducible $S$. cerevisiae 
Table 3. Effect of sec mutation on Sapt1 secretion by S. cerevisiae

\begin{tabular}{|llll|}
\hline Strain & Mutation & $\begin{array}{c}\text { Defective step in secretion at restrictive } \\
\text { temperature }\left(\mathbf{3 7}^{\circ} \mathbf{C}\right)\end{array}$ & $\begin{array}{c}\text { Accumulation of Sapt1 forms at restrictive } \\
\text { temperature }\left(37^{\circ} \mathbf{C}\right)\end{array}$ \\
\hline RSY455 & $\sec 61$ & Translocation across the ER & PPE \\
RSY12 & $\operatorname{sec53}$ & Glycosylation in the lumen & $\mathrm{PE}^{*}, \mathrm{PE}$ and M \\
HMS176 & $\sec 18$ & ER to Golgi apparatus transfer & $\mathrm{PE}^{*}$ \\
RSY9 & $\sec 7$ & Secretory vesicle formation & $\mathrm{PE}^{*}$ and $\mathrm{M}$ \\
RSY10 & $\operatorname{sec1}$ & Exocytosis & $\mathrm{PE}^{*}$ and $\mathrm{M}$ \\
\hline
\end{tabular}

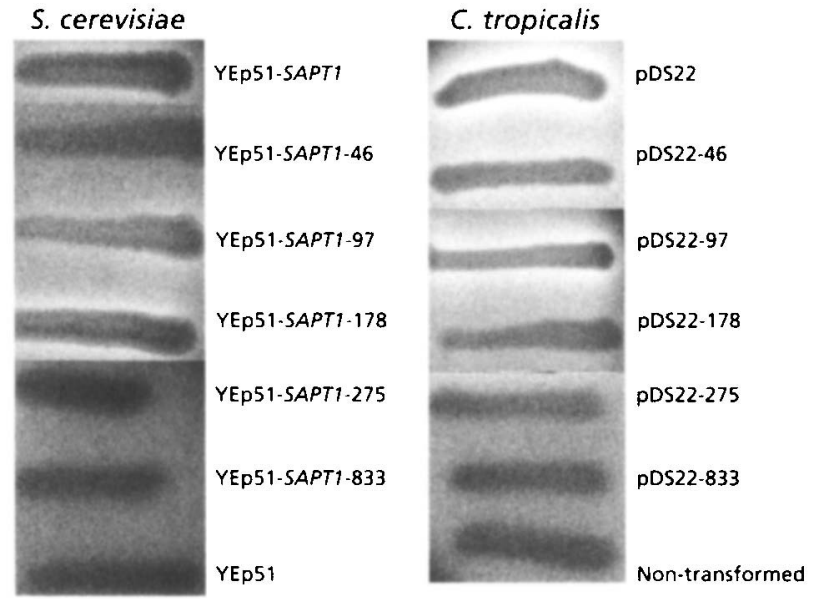

Fig. 2. Visual assay of secreted proteolytic activity in $S$. cerevisiae carrying SAPT1 and mutated forms of SAPT1. The plasmids harboured by each strain are indicated. C. tropicalis strains were grown on BSA agar and S. cerevisiae strains on glucose/galactose agar. Proteolytic activity was monitored after $4 \mathrm{~d}$ incubation at $30^{\circ} \mathrm{C}$.

GAL10 promoter. This recombinant plasmid and YEp51 were introduced in S. cerevisiae GRF18 and several sec mutants (Table 3). At non-restrictive temperature, the transformants harbouring YEp51-SAPT1 formed a clear zone around the colonies when grown on glucose/ galactose plates containing $0.4 \%$ BSA (Fig. 2) and secreted a $40 \mathrm{kDa}$ protein reacting against polyclonal antiSapt1 antiserum when grown in liquid galactose medium (data not shown). This finding indicated that the strains transformed with the YEp51-SAPT1 plasmid secreted the $\mathrm{M}$ form (see Fig. 4) of Sapt1.

\section{Precursors of Sapt1 in S. cerevisiae}

Two intracellular proteins were isolated by immunoprecipitation of radiolabelled products from $S$. cerevisiae GRF18 cells harbouring YEp51-SAPT1. Their estimated molecular masses on SDS-PAGE were $40 \mathrm{kDa}$ and $46 \mathrm{kDa}$, respectively (Fig. 3a). The lower band had the same mobility as the protein purified from the culture medium and therefore corresponds to the $\mathrm{M}$ form. Accumulation of this $46 \mathrm{kDa}$ protein was not affected when cells were treated with brefeldin A (Fig. 3a), a drug that blocks the translocation of the proteins through the Golgi apparatus, or in the sec 18 mutant at non-permissive temperature (Fig. 3b). However, S. cerevisiae cells treated with tunicamycin, a drug known to prevent protein glycosylation, like the sec53 mutant at non-permissive temperature, accumulated a $2 \mathrm{kDa}$ smaller precursor (Fig. $3 a, b)$. Therefore, we conclude that the $46 \mathrm{kDa}$ precursor of Sapt1 is an $N$-glycosylated protein located in the endoplasmic reticulum (ER). This observation is consistent with the presence of an $N$-glycosylation site at the position $\mathrm{Asn}^{50}$ in the propeptide sequence. The labels PE* and $\mathrm{PE}$ will refer henceforth to the glycosylated $46 \mathrm{kDa}$ and the unglycosylated $44 \mathrm{kDa}$ proenzymes, respectively (Fig. 4).

The mutants $\sec 1$ and $\sec 7$, which are defective in secretory vesicle formation and exocytosis respectively, accumulated the 46 and the $40 \mathrm{kDa}$ proteins at non-permissive temperature (Fig. 3b), suggesting that the processing step leading to the $M$ form formation took place in the Golgi apparatus.

In order to determine the size of Sapt1 preproenzyme, total RNA was extracted from $C$. tropicalis and translated in vitro. The immunoprecipitation of translated products permitted isolation of a protein with an estimated molecular mass of $45 \mathrm{kDa}$ (Fig. 3c), corresponding to the Sapt1 preproenzyme (PPE form), which is the nonprocessed precursor. Accumulation of PPE was observed in protein extracts of the $S$. cerevisiae sec 61 mutant grown at the non-permissive temperature (data not shown).

\section{Effect of point mutations on SAPT1 expressed in S. cerevisiae}

By introducing point mutations of the putative processing sites in the 60-amino-acid precursor peptide a systematic study was undertaken to analyse the role of cleavage sites in maturation and secretion of Sapt1. S. cerevisiae GRF18 was used as recipient for transformation with YEp51 plasmid carrying mutated forms of the $S A P T 1$ gene. To determine the presence of proteolytic activity, each transformant was grown on glucose/galactose medium containing $0.4 \%$ BSA (Fig. 2).

The strain harbouring YEp51-SAPT1-46 formed only a faint halo of clearing on glucose/galactose plates as compared to colonies carrying YEp51-SAPT1 (Fig. 2), indicating that the mutation of the signal sequence 

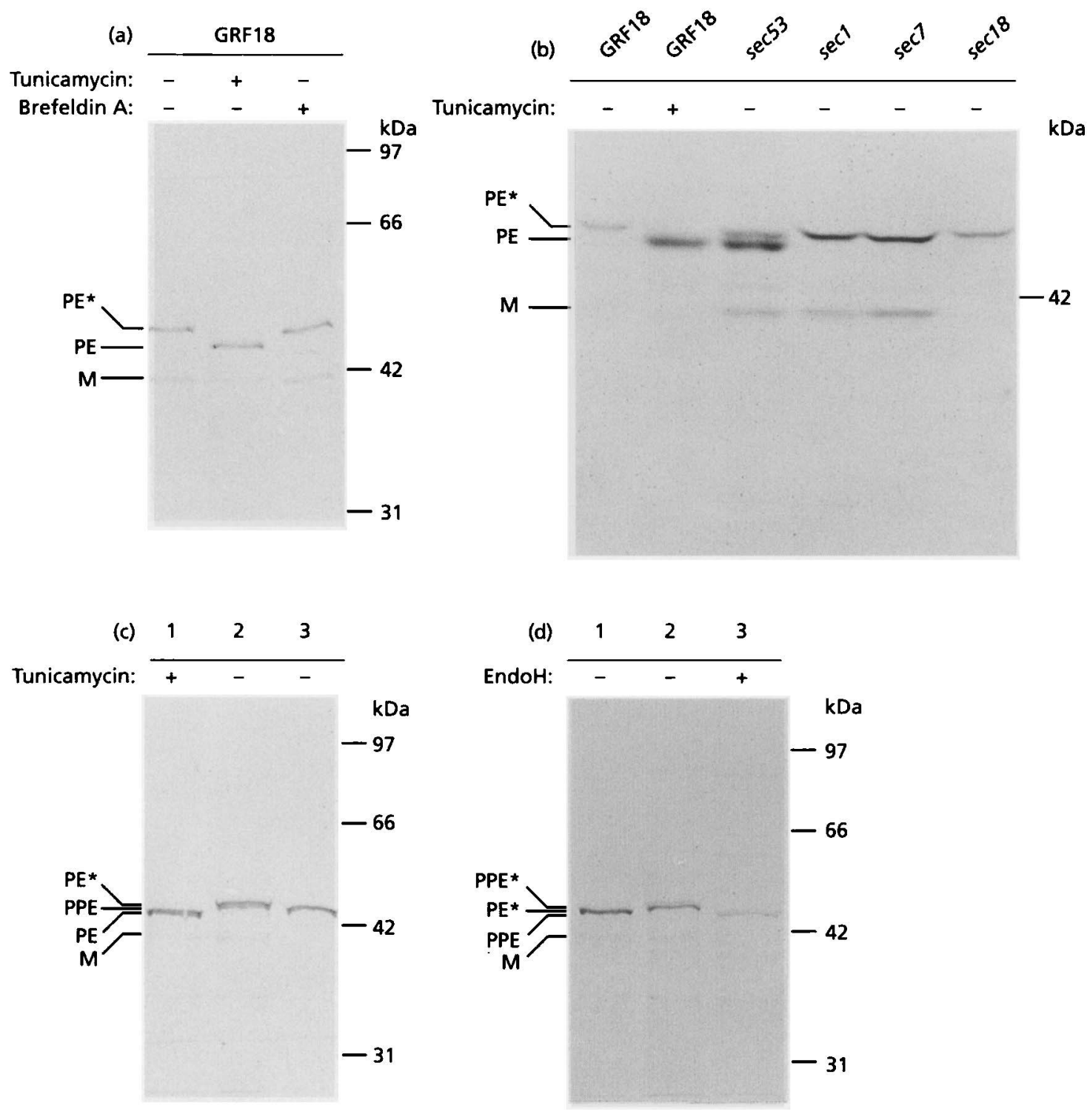

Fig. 3. Detection by immunoprecipitation of precursors and mature form of Sapt1. These experiments were performed with cell extracts of induced cultures of S. cerevisiae GRF18 and sec mutants and with products from in vitro translation of total RNA of induced $C$. tropicalis cells. Inductions were performed as indicated in Methods. Proteins were radiolabelled by addition of $50 \mu \mathrm{Ci}(1.85 \mathrm{MBq})$ Trans ${ }^{35} \mathrm{~S}$-Label to $1.0 \mathrm{OD}_{660}$ of yeast cells or to $5 \mu \mathrm{g}$ of total RNA. Immunoprecipitated proteins were separated by SDS-PAGE ( $9 \%$ polyacrylamide) and detected by fluorography. The positions and apparent molecular masses of marker proteins (phosphorylase $b, 97 \mathrm{kDa}$; bovine serum albumin, $66 \mathrm{kDa}$; ovalbumin, $42 \mathrm{kDa}$; carbonic anhydrase, $31 \mathrm{kDa})$ are shown on the right of each gel. (a) Effects of tunicamycin (10 $\mu \mathrm{g}$ $\mathrm{ml}^{-1}$ ) and brefeldin A $\left(5 \mu \mathrm{g} \mathrm{m}^{-1}\right)$ on Sapt 1 in S. cerevisiae GRF18 carrying the YEp51-SAPT1 plasmid. Drug treatments were performed for $1 \mathrm{~h}$ at $30^{\circ} \mathrm{C}$. (b) Intracellular Sapt1 precursors in S. cerevisiae GRF18 carrying the YEp51-SAPT1 plasmid in the presence $(+)$ or absence $(-)$ of tunicamycin $\left(10 \mu \mathrm{g} \mathrm{ml}^{-1}\right)$ and accumulation at the restrictive temperature of $37^{\circ} \mathrm{C}$ of Sapt1 precursors by S. cerevisiae sec mutants (sec1, sec7, sec18 and sec53) harbouring the YEp51-SAPT1 plasmid. (c) Detection by immunoprecipitation of proteins from $S$. cerevisiae GRF18 cells carrying the YEp51-SAPT1 plasmid (lane 1, PE; lane 2, PE*) and of products from in vitro translation of total RNA from a $26 \mathrm{~h}$ induced culture of $C$. tropicalis ATCC 750 (lane 3, PPE). Before protein extraction S. cerevisiae GRF18 cultures were treated (lane 1) or not (lane 2) with tunicamycin $\left(10 \mu \mathrm{g} \mathrm{ml}^{-1}\right)$ for $1 \mathrm{~h}$. (d) Detection by immunoprecipitation of intracellular Sapt1 precursors in $S$. cerevisiae GRF18 transformed with (lane 1, PE*) YEp51-SAPT1 and (lane 2, PPE*; lane 3, PPE) YEp51-SAPT1-46. Cell extracts were treated $(+)$ or not $(-)$ with endoglycosidase $H$ (Monod et al., 1989).

cleavage sites reduced secretion of Sapt1. In liquid galactose medium this strain secreted the $40 \mathrm{kDa} \mathrm{M}$ form of Sapt1 (data not shown). The analysis of the Sapt1 precursors in cell extracts revealed the presence of an additional $47 \mathrm{kDa}$ protein (PPE*, Fig. 3d). The $47 \mathrm{kDa}$ PPE* was converted to PPE by endoglycosidase $\mathrm{H}$ treatment (Fig. 3d), indicating that the PPE* was glycosylated. 


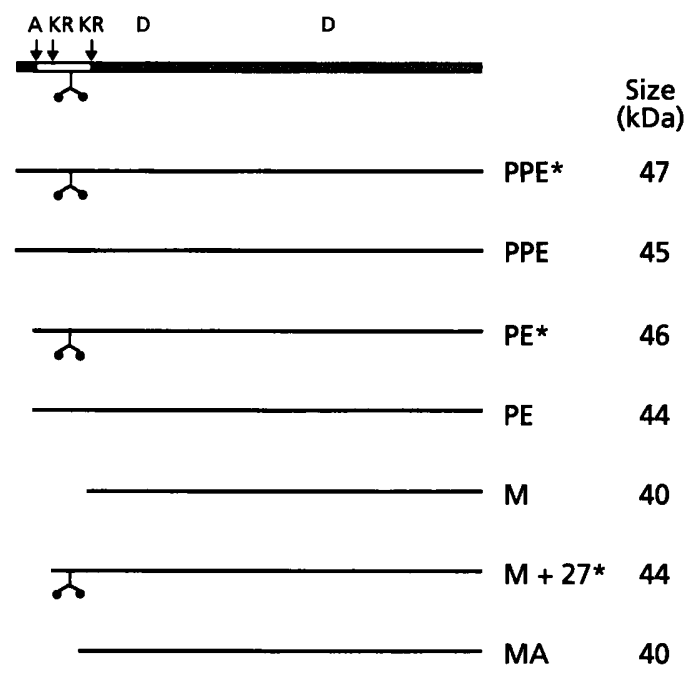

Fig. 4. List of the Sapt1 forms, with their code and molecular size. A model of Sapt 1 is given at the top, indicating the signal sequence (black box), the proregion (open rectangle), the mature sequence (diagonal lines), the putative processing sites (arrows) and amino acids in these regions analysed in this study (one-letter code).

The proteolytic haloes around the colonies of yeasts harbouring YEp51-SAPT1, YEp51-SAPT1-97 and YEp51-SAPT1-178 were not significantly different from one another, indicating that mutation of one of the two Lys-Arg sites did not affect the activity of the secreted enzyme. The strain carrying the YEp51-S APT1-97 plasmid (mutation of the $\mathrm{Lys}^{32}-\mathrm{Arg}^{33}$ site) showed the same intracellular precursors and secreted form of Sapt1 as the strain carrying the YEp51-SAPT1 plasmid (data not shown). In contrast, two proteins were present in the supernatant of the culture of cells transformed with the YEp51-SAPT1-178 plasmid, which encoded proteins lacking the $\mathrm{Lys}^{59}-\mathrm{Arg}^{60}$ site immediately upstream of the $\mathrm{N}$-terminus of the mature form of Sapt1 (Fig. 5a). The larger protein migrated as a protein with a molecular mass of $44 \mathrm{kDa}$ and its initial seven $\mathrm{N}$-terminal amino acid residues were determined to be Thr-Asp-Lys-Val-ValSer-Leu. This protein corresponded to the predicted Sapt1 form cleaved at the $\mathrm{Lys}^{32}-\mathrm{Arg}^{33}$ site, 27 amino acids upstream of the $\mathrm{N}$-terminal amino acid of the $\mathrm{M}$ form; it was therefore named the $\mathrm{M}+27^{*}$ form (Fig. 4). The smaller protein (MA form) migrated as a protein slightly larger than the $\mathrm{M}$ form. The initial $10 \mathrm{~N}$-terminal amino acid residues were determined to be Ile-Gln-Lys-Gly-SerAsp-Val-Pro-Thr-Thr, indicating that the MA form is four amino acid residues longer than the $M$ form. The two proteins $\mathrm{M}+27^{*}$ and $\mathrm{MA}$ were present at the same time. However, over the course of time the upper band was diminished and the signal of the lower band intensified, suggesting that cleavage was taking place in the growth medium (Fig. 5a). This shift was observed even in the absence of cells (Fig. 5b). In order to verify that this cleavage was the consequence of an autocatalytic activity by Sapt1, pepstatin $A$ was added to the supernatant and the reaction mixture was incubated at $30^{\circ} \mathrm{C}$. Pepstatin A (a)

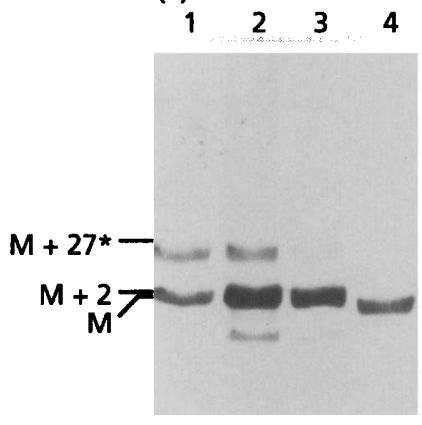

(b)

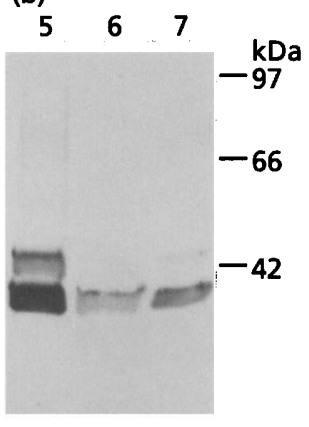

Fig. 5. Forms of Sapt 1 secreted by S. cerevisiae GRF18 carrying the YEp51-SAPT1-178 plasmid. (a) In lanes 1, 2 and 3, the proteins were recovered from the supernatant of an induced culture at different incubation times (lane 1, $10 \mathrm{~h}$; lane 2, $30 \mathrm{~h}$; lane 3,50 h) and analysed by Western blotting. Their apparent molecular masses were compared to that of the $40 \mathrm{kDa} M$ form (lane 4). The fast-migrating band (lane 2) was identified as a degradation product of the enzyme. Similar results were obtained with other proteinases, such as alkaline proteinase secreted by Aspergillus fumigatus (Monod et al., 1991). (b) In lanes 5 and 6 , samples of cell-free supernatant from the $10 \mathrm{~h}$ induced culture were incubated at $30^{\circ} \mathrm{C}$ in the presence (lane 5) or absence (lane 6) of pepstatin $A\left(40 \mu \mathrm{g} \mathrm{ml}^{-1}\right)$ and the proteins were compared to the Sapt1 form present in the $50 \mathrm{~h}$ induced culture (lane 7). When testing for inhibition of autocatalytic cleavage, pepstatin $A\left(40 \mu \mathrm{g} \mathrm{ml}^{-1}\right)$ was added to the supernatant of $S$. cerevisiae cultures and the incubation at $30^{\circ} \mathrm{C}$ was continued for $10 \mathrm{~h}$ before TCA precipitation.

is a specific inhibitor of enzymes belonging to the pepsin family. Under these conditions, the intensity of the upper $\mathrm{M}+27^{*}$ form remained unaffected (Fig. 5b), confirming that the smaller MA form was an autocleavage product of the $\mathrm{M}+27^{*}$ Sapt1.

Colonies of cells carrying the double mutation YEp51$S A P T 1-97 / 178$ formed no haloes (Fig. 2) and no Sapt1 was detected in the growth medium of a culture of yeast cells carrying this plasmid. The same results were obtained with $S$. cerevisiae GRF18 harbouring the YEp51-SAPT1$178 / 275$ plasmid and the $S$. cerevisiae $\operatorname{Tr} 1625$ kex 2 strain transformed with the YEp51-UR A3-SAPT1 plasmid. Immunoprecipitation of radiolabelled proteins from these three strains revealed the presence of the $46 \mathrm{kDa} \mathrm{PE}^{*}$ form (data not shown).

The transformants harbouring the YEp51-SAPT1-275 and YEp51-SAPT1-833 plasmids, which encoded Sapt1 proteins with mutated active sites, were also unable to hydrolyse BSA (Fig. 2). These mutants showed the same intracellular precursors and secreted form of Sapt1 as the strain carrying the YEp51-SAPT1 plasmid (data not shown).

\section{In vivo expression of Sapt1 by C. tropicalis}

The kinetics of Sapt1 production by C. tropicalis ATCC 750 in induction medium was monitored by radiolabelling and immunoprecipitation of proteins after different incubation times. The analysis of supernatant samples 


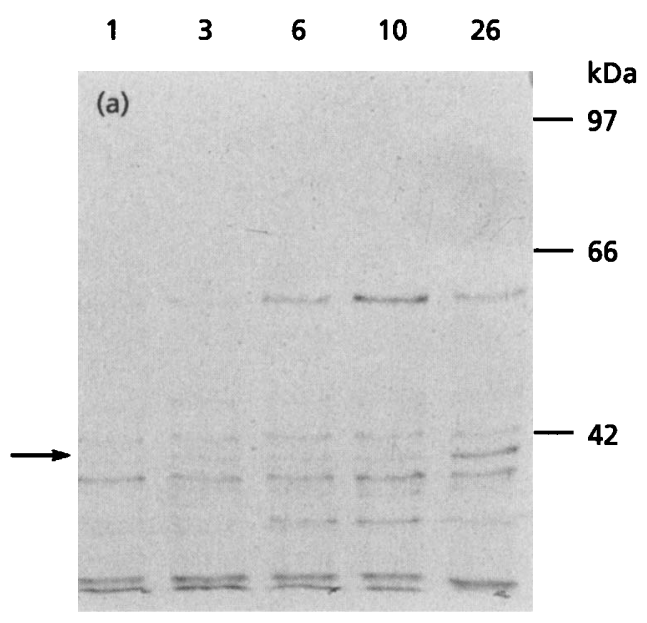

(b)

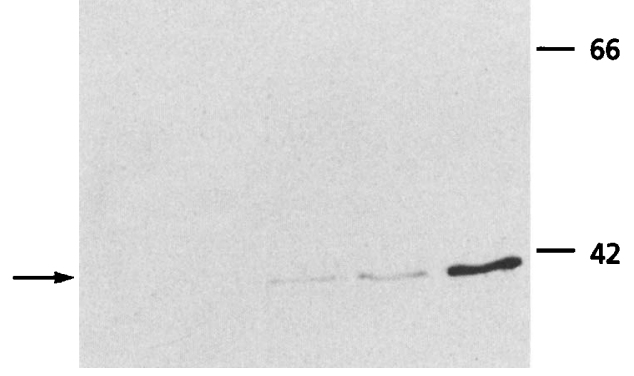

Fig. 6. Kinetics of Sapt1 production by $C$. tropicalis. After different times $(1,3,6,10,26 \mathrm{~h})$ of growth in Sapt1 induction medium, $1 \mathrm{ml}$ cell suspension was mixed with $50 \mu \mathrm{Ci}(1.85 \mathrm{MBq})$ Trans ${ }^{35} \mathrm{~S}$-Label and incubated for $120 \mathrm{~min}$ at $30^{\circ} \mathrm{C}$. Proteins from cell extracts (a) and medium supernatant (b) were immunoprecipitated using $5 \mu \mathrm{l}$ polyclonal anti-Sapt1 specific rabbit antiserum, separated by SDS-PAGE using a $7.5 \%$ polyacrylamide gel and analysed by fluorography (Chamberlain, 1979). The arrows indicate the position of the $M$ form of Sapt1. The molecular size markers are the same as for Fig. 3.

permitted observation of the $40 \mathrm{kDa} M$ form after $6 \mathrm{~h}$ incubation, with the highest signal intensity observed after $26 \mathrm{~h}$, at the end of the observation interval (Fig. 6). The analysis of intracellular precursors of Sapt1 was not possible with the antiserum (Fig. 6) or with the monoclonal antibodies (data not shown) because of the presence of several interfering reacting products. Therefore, we decided to investigate the role of the preproregion by the analysis of the effects of $S A P T 1$ gene point mutations on $C$. tropicalis growth, proteolytic activity on BSA plates and Sapt1 secretion in BSA liquid medium. C. tropicalis DSY59, which is a sapt1, ade2 mutant, was transformed with pDS22 carrying mutations in the SAPT1 gene. The presence of the plasmid in each strain was verified by extraction of the plasmids from yeast cells and analysis on agarose gels after digestion with restriction enzymes. The transformants were stable when maintained on MM plates.

On BSA plates clear zones were observed only around colonies harbouring pDS22, pDS22-46 or pDS22-97 (Fig. 2 ), indicating that the mutation of the signal sequence

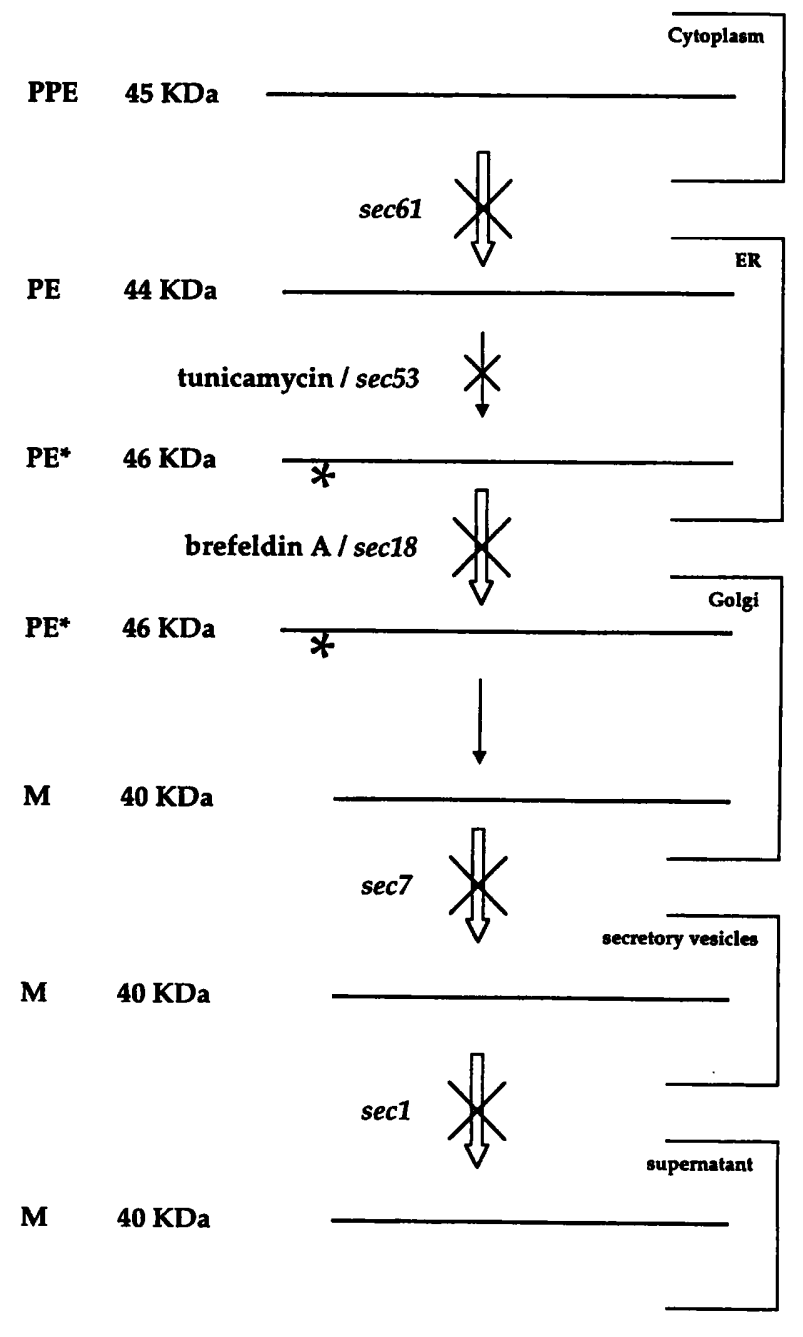

Fig. 7. Summary of the Sapt1 maturation pathway. The figure is explained in the discussion. To the left of the figure are indicated the name and the apparent molecular mass of each intermediate. Open arrows signify an inter-organelle translocation step and closed arrows an intra-organelle processing step. Gene names are placed so as to indicate which Sapt1 precursor accumulates in sec mutants. The asterisk represents the Asn-linked carbohydrate chain.

cleavage site and the $\mathrm{Lys}^{32}-\mathrm{Arg}^{33}$ site did not affect the enzymic activity of the yeast on solid medium. These strains were able to grow in BSA liquid medium and to secrete the M form of Sapt1 (data not shown). Only a faint clearing zone was observed around the colonies carrying pDS22-178 (Lys ${ }^{59}-\mathrm{Arg}^{60}$ site mutated). However, neither this strain, nor the $C$. tropicalis sapt1 mutant, grew in BSA liquid medium. The transformants harbouring pDS22275 or pDS22-833, which encoded Sapt1 proteins with mutated active sites, grew neither on BSA plates nor in liquid BSA medium, presumably because the inability to hydrolyse BSA meant that they lacked a nitrogen source.

\section{DISCUSSION}

Secreted proteinases are normally translated as larger precursors which are subsequently processed during 
Table 4. Effects of SAPT1 point mutations on Sapt1 secretion by S. cerevisiae

\begin{tabular}{|c|c|c|c|}
\hline \multirow[t]{2}{*}{ Plasmid } & \multirow[t]{2}{*}{ Characteristics } & \multicolumn{2}{|c|}{ SAPT1 forms produced } \\
\hline & & Intracellular & Secretion \\
\hline YEp51 & Parent plasmid & Not detected & Not detected \\
\hline YEp51-SAPT1 & YEp51 carrying SAPT1 & $\mathrm{PE}^{*}$ and $\mathrm{M}$ & M \\
\hline YEp51-SAPT1-46 & Signal sequence cleavage site mutated $\left(\mathrm{Ala}^{16} \rightarrow \mathrm{Pro}^{16}\right)$ & $\begin{array}{l}\mathrm{PPE}^{*}, \mathrm{PE}^{*} \\
\text { and } \mathrm{M}\end{array}$ & M \\
\hline YEp51-SAPT1-97 & Lys $^{32}-\mathrm{Arg}^{33}$ site mutated $\left(\mathrm{Arg}^{33} \rightarrow \mathrm{Gly}^{33}\right)$ & $\mathrm{PE}^{*}$ and $\mathrm{M}$ & M \\
\hline YEp51-SAPT1-178 & Lys $^{59}-\mathrm{Arg}^{60}$ site mutated $\left(\mathrm{Arg}^{60} \rightarrow \mathrm{Gly}^{60}\right)$ & PE* & $\begin{array}{l}M+27^{*} \\
\text { and } M+4\end{array}$ \\
\hline YEp51-SAPT1-97/178 & Both Lys-Arg sites mutated $\left(\mathrm{Arg}^{33} \rightarrow \mathrm{Gly}^{33}, \mathrm{Arg}^{60} \rightarrow \mathrm{Gly}^{60}\right)$ & PE* & Not detected \\
\hline YEp51-SAPT1-275 & Active site mutated $\left(\mathrm{Asp}^{92} \rightarrow \mathrm{Val}^{92}\right)$ & $\mathrm{PE}^{*}$ and $\mathrm{M}$ & Inactive $\mathrm{M}$ \\
\hline YEp51-SAPT1-833 & Active site mutated $\left(\mathrm{Asp}^{278} \rightarrow \mathrm{Val}^{278}\right)$ & $\mathrm{PE}^{*}$ and $\mathrm{M}$ & Inactive $\mathrm{M}$ \\
\hline YEp51-SAPT1-178/275 & $\mathrm{Lys}^{59}-\mathrm{Arg}^{60}$ site $\left(\mathrm{Arg}^{60} \rightarrow \mathrm{Gly}^{60}\right)$ and active site mutated $\left(\mathrm{Asp}^{92} \rightarrow \mathrm{Val}^{92}\right)$ & PE* & Not detected \\
\hline YEp51-URA3-SAPT1 & Non-mutated Sapt1 & PE* & Not detected \\
\hline
\end{tabular}

secretion. The nucleotide sequence of the entire $S A P T 1$ gene suggested that the enzyme is translated as a preproform, 60 amino acids larger than the mature Sapt1. A putative precursor of Sap from $C$. albicans was described by Homma et al. (1992, 1993) and Benerjee et al. (1991), but the processing mechanism was not investigated. In $S$. cerevisiae, transcription of $S A P T 1$ resulted in secretion of the active enzyme identical to that secreted by $C$. tropicalis. The analysis of $S$. cerevisiae GRF18 and sec mutant products (results summarized in Table 3 ) as well as the drug effects on Sapt1 secretion (Fig. 3a) allowed us to propose a secretion mechanism for this enzyme shown in Fig. 7. Only the PE* precursor was observed in cell extracts of $S$. cerevisiae GRF18. After translocation into the Golgi apparatus, the glycosylated $46 \mathrm{kDa} \mathrm{PE}^{*}$ precursor form undergoes proteolytic cleavage by the Kex2 endopeptidase, generating the $40 \mathrm{kDa} \mathrm{M}$ form. The $\mathrm{M}$ form of Sapt1 is sorted into secretory vesicles and finally released into the extracellular space (Fig. 7).

The mutation of the signal peptidase cleavage site does not affect the ability of the mutated protein to cross the ER membrane and to be processed correctly, but it leads to a decrease of Sapt1 secretion as deduced from BSA plate analysis (Table 4). Previous studies of $S$. cerevisiae acid phosphatase secretion (Monod et al., 1989) showed that signal sequence cleavage was not necessary for the entry of proteins into the secretory pathway, but was important for efficient secretion. The mutation of the $\mathrm{Lys}^{32}-\mathrm{Arg}^{33}$ site alone does not affect Sapt1 maturation and secretion (Table 4). Modification of the $\mathrm{Lys}^{59}-\mathrm{Arg}^{60}$ site, which just precedes the $\mathrm{N}$-terminal amino acid of the $40 \mathrm{kDa} M$ form of Sapt1, did not affect secretion of the Sapt1 protein. However, this form was four amino acids longer than the $\mathrm{M}$ form, as observed by the $\mathrm{N}$-terminal amino acid sequencing of this MA form of Sapt1. The MA protein is produced by an autocatalytic cleavage step since pepstatin A, a specific inhibitor of aspartic proteinases, prevented the conversion of the $\mathrm{M}+27^{*}$ form into the MA form. Similar results were obtained by $\mathrm{Lin}$ et al.
(1993), who cloned the $S A P T 1$ gene into a T7 expression vector of $E$. coli. The purified unprocessed precursor of Sapt1, corresponding to the unglycosylated $45 \mathrm{kDa} P P E$ form of our study, was converted to the Sapt1 mature form by autocatalytic processing under acidic conditions. The N-terminal sequence analysis revealed a mixture of two sequences corresponding to proteins one and two amino acids longer than the $M$ form. In the experimental conditions of Lin et al. (1993), autocatalytic cleavage of unglycosylated PPE in vitro can only be initiated by selfhydrolysis. However, further hydrolysis of unprocessed Sapt1 molecules by processed ones can not be excluded. The amino acid position of the autocatalytic cleavage site appears to be substrate dependent since it is different for unglycosylated PPE and $\mathrm{M}+27$ forms.

No Sapt1 secreted protein was found during the expression by $S$. cerevisiae GRF18 of the $S A P T 1$ gene with both the Lys-Arg sites mutated, nor during expression of the unmutated $S A P T 1$ gene by $S$. cerevisiae $\operatorname{Tr} 1625$, which is a kex 2 mutant. In the present case, to obtain the Sapt1 mature form, Kex2 can not be substituted by any other endopeptidase such as Yap3 (Egel-Mitani et al., 1990; Ash et al., 1995). These results, obtained with $S$. cerevisiae, suggest that the removal of the proregion is required for the secretion of the Sapt1.

Neither the antiserum nor the monoclonal antibodies permitted the analysis of intracellular precursors of Sapt1 in $C$. tropicalis because of the presence of several crossreacting components. Therefore, we analysed the role of the putative processing sites present in the preproregion by studying the effect of $S A P T 1$ point mutations on proteolytic activity secreted by $C$. tropicalis. The results, summarized in Table 5 , are consistent with those obtained with $S$. cerevisiae. Growth in BSA liquid medium was observed only with strains able to produce the $40 \mathrm{kDa}$ form of Sapt1, like the wild-type C. tropicalis ATCC 750 and the sapt1 mutant carrying pDS22, as well as the strains producing the Sapt1 precursor with a mutated signal sequence cleavage site or $\mathrm{Lys}^{32}-\mathrm{Arg}^{33}$ site. In contrast, the 
Table 5. Effects of SAPT1 point mutations on Sapt1 secretion by C. tropicalis

\begin{tabular}{|c|c|c|c|}
\hline \multirow[t]{2}{*}{ Plasmid } & \multirow[t]{2}{*}{ Characteristics } & \multicolumn{2}{|c|}{ Effects on $C$. tropicalis Sapt1 secretion } \\
\hline & & BSA plates & BSA liquid medium \\
\hline pDS22 & Non-mutated Sapt1 & Halo & Living cells; mature Sapt 1 secretion \\
\hline pDS22-46 & Signal sequence cleavage site mutated $\left(\mathrm{Ala}^{16} \rightarrow \operatorname{Pro}^{16}\right)$ & Halo & Living cells; mature Sapt 1 secretion \\
\hline pDS22-97 & Lys $^{32}-\operatorname{Arg}^{33}$ site mutated $\left(\mathrm{Arg}^{33} \rightarrow \mathrm{Gly}^{33}\right)$ & Halo & Living cells; mature Sapt 1 secretion \\
\hline pDS22-178 & Lys $^{59}-$ Arg $^{60}$ site mutated $\left(\operatorname{Arg}^{60} \rightarrow \mathrm{Gly}^{60}\right)$ & Faint halo & Death; Sapt not detected \\
\hline pDS22-275 & Active site mutated $\left(\mathrm{Asp}^{92} \rightarrow \mathrm{Val}^{92}\right)$ & - & Death; Sapt not detected \\
\hline pDS22-833 & Active site mutated $\left(\mathrm{Asp}^{278} \rightarrow \mathrm{Val}^{278}\right)$ & - & Death; Sapt not detected \\
\hline
\end{tabular}

$\mathrm{Lys}^{59}-\mathrm{Arg}^{60}$ mutation blocked growth in this Sapt1 induction medium. Mutation of $\mathrm{Lys}^{59}-\mathrm{Arg}^{60}$ led either to a decrease of the secretion of active Sapt1 or to the production of a Sapt1 with reduced enzymic activity (Fig. 2). In both cases the growth of this mutant in BSA liquid medium is dramatically affected because the yeast lacks a nitrogen source. Our results suggest that an endopeptidase similar to $\mathrm{Kex} 2$ is present in C. tropicalis.

The processing of proenzymes to the mature form is achieved either by autocatalytic cleavage (Hiramatsu $\mathrm{et}$ al., 1989; Miyazaki et al., 1989; Silen et al., 1989) or by specific endopeptidases (Vos et al., 1989). In S. cerevisiae the nonmutated form of Sapt1 is processed by the specific endopeptidase Kex2. Examination of precursors and their derived peptides has shown that most proteolytic processing occurs after di- or tetrabasic amino acid sequences, and several endopeptidases, structurally related to Kex2, have been described as being involved in this specific cleavage. The widespread distribution of this stepwise cleavage mechanism could be explained by its efficiency (for a review see Van de Ven et al., 1993). The autocatalytic cleavage observed when the $\mathrm{Lys}^{59}-\mathrm{Arg}^{60}$ site was mutated indicates that the yeast possesses an alternative, less efficient way to produce the mature form of Sapt1. Sapt1 is a unique case where the processing of a proenzyme can be achieved either by a specific endopeptidase or by an autocleavage.

\section{ACKNOWLEDGEMENTS}

G. Togni performed this work in partial fulfilment of the requirements for a $\mathrm{PhD}$ degree from the University of Lausanne (Switzerland). The authors are indebted to $\mathrm{Dr} \mathrm{R}$. HaguenauerTsapis and Dr A. Hinnen for sending he S. cerevisiae strains and to Dr M. Borg-von Zepelin for providing the monoclonal antibody. They thank Dr H. Pooley for helpful comments on the manuscript.

\section{REFERENCES}

Ash, J., Dominguez, M., Bergeron, J. J. M., Thomas, D. Y. \& Bourbonnais, Y. (1995). The yeast proprotein convertase encoded by $Y A P 3$ is a glycophosphatidylinositol-anchored protein that localizes to the plasma membrane. J Biol Chem 270, 20847-20854.

Benerjee, A., Genesan, K. \& Detta, A. (1991). Induction of secretory acid proteinase in Candida albicans. J Gen Microbiol 137, 2455-2461.
Chamberlain, J. P. (1979). Fluorographic detection of radioactivity in polyacrylamide gels with the water soluble fluor, sodium salicylate. Anal Biochem 98, 132-135.

Chomczynski, P. \& Sacchi, N. (1987). Single-step of RNA isolation by guanidium thiocyanate-phenol-chloroform extraction. Anal Biochem 162, 156-159.

Doms, R. W., Russ, G. \& Yewdell, J. W. (1989). Brefeldin A redistributes resident and itinerant Golgi proteins to the endoplasmic reticulum. J Cell Biol 109, 61-72.

Duksin, D., Seiberg, M. \& Mahoney, W. C. (1982). Inhibition of protein glycosylation and selective cytotoxicity toward virally transformed fibroblasts caused by $\mathrm{B}_{3}$-tunicamycin. Eur $\mathrm{J}$ Biochem, 129, 77-80.

Egel-Mitani, M., Flygenring, H. P. \& Hansen, M. T. (1990). A novel aspartyl protease allowing $K E X 2$-independent $M F \propto$ propheromone processing in yeast. Yeast 6, 127-137.

Franzusoff, A., Rothblatt, J. \& Schekman, R. (1991). Analysis of polypeptide transit through yeast secretory pathway. Methods Enzymol 194, 662-674.

Gibson, T. J. (1984). Studies on the Epstein-Barr virus genome. $\mathrm{PhD}$ thesis, Cambridge University, UK.

Hanahan, D. (1983). Studies on transformation of Eschericha coli with plasmids. $J$ Mol Biol 166, 557-580.

Hiramatsu, R., Aikawa, J., Horinouchi, S. \& Beppu, T. (1989). Secretion by yeast of the zymogen form of Mucor rennin, an aspartic proteinase of Mucor pusillus, and its conversion to the mature form. $J$ Biol Chem 264, 16862-16866.

Homma, M., Kanbe, T., Chibana, H. \& Tanaka, K. (1992). Detection of intracellular forms of secretory aspartic proteinase in Candida albicans. J Gen Microbiol 138, 627-633.

Homma, M., Chibana, H. \& Tanaka, K. (1993). Induction of extracellular proteinase in Candida albicans. $J$ Gen Microbiol 139, 1187-1193.

Horn, R., Wong, B., Kiehn, T. E. \& Armstrong, D. (1985). Fungemia in a cancer hospital: changing frequency, earlier onset, and results of therapy. Rev Infect Dis 7, 646-654.

Hube, B., Turver, C. J., Odds, F. C., Eiffert, H., Boulnois, G. J., Kbchel, H. \& Ruchel, R. (1991). Sequence of the Candida albicans gene encoding the secretory aspartate proteinase. J Med Vet Mycol 29, 129-132.

Hube, B., Monod, M., Schofield, A., Brown, A. J. P. \& Gow, N. A. R. (1994). Expression of seven members of the gene family encoding secretory aspartyl proteinases in Candida albicans. Mol Microbiol 14, 87-99.

Innis, M. A., Gelfand, D. H., Sninsky, J. J. \& White, T. J. (1990). PCR Protocols: a Guide to Methods and Applications. San Diego: Academic Press. 
Ito, H., Fukuda, Y., Murata, K. \& Kimura, A. (1983). Transformation of intact yeast cells treated with alkali cations. J Bacteriol 153, 163-168.

Julius, D., Brake, A., Blair, L., Kunisawa, R. \& Thorner, J. (1984). Isolation of the putative structural gene for the lysine-argininecleaving endopeptidase required for processing of yeast prepro- $\alpha$ factor. Cell 37, 1075-1089.

Kunkel, T. A., Roberts, J. D. \& Zakour, R. A. (1987). Rapid and efficient site-specific mutagenesis without phenotypic selection. Methods Enzymol 154, 367-382.

Kwon-Chung, K. J. \& Bennett, J. E. (1992). Candidiasis. In Medical Mycology, pp. 280-336. Edited by K. J. Kwon-Chung \& J. E. Bennett. Philadelphia, PA: Lea \& Febiger.

Laemmli, U. K. (1970). Cleavage of structural proteins during the assembly of the head of bacteriophage T4. Nature 227, 680-685.

Lin, X., Tang, J., Koelsch, G., Monod, M. \& Foundling, S. (1993). Recombinant canditropsin, an extracellular aspartic protease from yeast Candida tropicalis. J Biol Chem 268, 20143-20147.

Miyasaki, S. H., White, T. C. \& Agabian, N. (1994). A fourth secreted aspartyl proteinase gene $(S A P 4)$ and a $C A R E 2$ repetitive element are located upstream of the $S A P 1$ gene in Candida albicans. J Bacteriol 176, 1702-1710.

Miyazaki, H., Yanagida, N., Horinouchi, S. \& Beppu, T. (1989). Characterization of the precursor of Serratia marcescens serine protease and $\mathrm{COOH}$-terminal processing of the precursor during its excretion through the outer membrane of Escherichia coli. $J$ Bacteriol 171, 6566-6572.

Monod, M., Haguenauer-Tsapis, R., Rauseo-König, I. \& Hinnen, A. (1989). Functional analysis of the signal-sequence processing site of yeast acid phosphatase. Eur J Biochem 182, 213-221.

Monod, M., Togni, G., Rahalison, L. \& Frenk, E. (1991). Isolation and characterisation of an extracellular alkaline protease of Aspergillus fumigatus. J Med Microbiol 35, 23-28.

Monod, M., Togni, G., Hube, B. \& Sanglard, D. (1994). Multiplicity of genes encoding secreted aspartic proteases in Candida species. Mol Microbiol 13, 357-368.

Morrow, B., Srikantha, T. \& Soll, D. R. (1992). Transcription of the gene for a pepsinogen, PEP1, is regulated by white-opaque switching in Candida albicans. Mol Cell Biol 12, 2997-3005.

Odds, F. C. (1988). Candida and Candidosis: a Review and Bibliograpby, 2nd edn. London: Ballière Tindall.

Ogrydziak, D. M. (1993). Yeast extracellular proteases. Crit Rev Biotecbnol 13, 1-55.

Rose, M. D. \& Broach, J. R. (1991). Cloning genes by complementation in yeast. Methods Enzymol 194, 195-230.

Sanglard, D., Togni, G., de Viragh, P. A. \& Monod, M. (1992). Disruption of the gene encoding the secreted acid protease (ACP) in the yeast Candida tropicalis. FEMS Microbiol Lett 95, 149-156.
Sato, T., Tsunasawa, S., Nakamura, Y., Emi, M., Sakayama, F. \& Matsubara, K. (1986). Expression of the human salivary $\alpha$-amylase gene in yeast and characterization of the second protein. Gene 50, $247-257$.

Sengstag, C. \& Hinnen, A. (1987). The sequence of the Saccharomyces gene $\mathrm{PHO} 2$ codes for a regulatory protein with unusual aminoacid composition. Nucleic Acids Res 15, 233-246.

Silen, J. L., Frank, D., Fujishige, A., Bone, R. \& Agard, D. A. (1989). Analysis of prepro- $\alpha$-lytic protease expression in Escherichia coli reveals that the pro region is required for activity. $J$ Bacteriol 171, 1320-1325.

Tatsumi, H., Ogawa, Y., Murakami, S., Ishida, Y., Murakami, K., Masaki, A., Kawabe, H., Arimura, H., Nakano, E. \& Motai, H. (1989). A full length cDNA clone for the alkaline protease from Aspergillus oryzae: structural analysis and expression in Saccharomyces cerevisiae. Mol \& Gen Genet 219, 33-38.

Togni, G., Sanglard, D., Falchetto, R. \& Monod, M. (1991). Isolation and nucleotide sequence of the extracellular acid protease gene (ACP) from the yeast Candida tropicalis. FEBS Lett 286, 181-185.

Van de Ven, W. J., Roebroek, A. J. \& Duijnhoven, H. L. (1993). Structure and function of eukaryotic proprotein processing enzymes of the subtilisin family of serine proteases. Crit Rev Oncol 4, 115-136.

de Viragh, P. A., Sanglard, D., Togni, G., Falchetto, R. \& Monod, M. (1993). Cloning and sequencing of two Candida parapsilosis genes encoding acid proteases. J Gen Microbiol 139, 335-342.

Von Heijne, G. (1986). A new method for predicting signal sequence cleavage sites. Nucleic Acids Res 14, 4683-4690.

Vos, P., van Asseldonk, M., van Jeveren, F., Siezen, R., Simons, G. \& de Vos, W. M. (1989). A maturation protein is essential for production of active forms of Lactococcus lactis SK11 serine proteinase located in or secreted from the cell envelope. $J$ Bacteriol 171, 2795-2802.

White, T. C., Miyasaki, S. H. \& Agabian, N. (1993). Three distinct secreted aspartyl proteinases in Candida albicans. J Bacteriol 175, 6126-6133.

Wingard, J. R., Merz, W. G. \& Saral, R. (1979). Candida tropicalis: a major pathogen in immunocompromised patients. Ann Intern Med 91, 539-543.

Wright, R. J., Carne, A., Hieber, A. D., Lamont, I. L., Emerson, G. W. \& Sullivan, P. A. (1992). A second gene for a secreted aspartate proteinase in Candida albicans. J Bacteriol 174, 7848-7853.

Yamashita, T., Tonouchi, N., Uozumi, T. \& Beppu, T. (1987). Secretion of the Mucor rennin, a fungal aspartic protease of Mucor pusillus, by recombinant yeast cells. Mol \& Gen Genet 210, 462-467.

Received 31 July 1995; revised 22 November 1995; accepted 6 December 1995. 